Proceedings of the International Congress on Advances in Applied Physics and Materials Science, Antalya 2011

\title{
Bioceramic Production from Sea Urchins
}

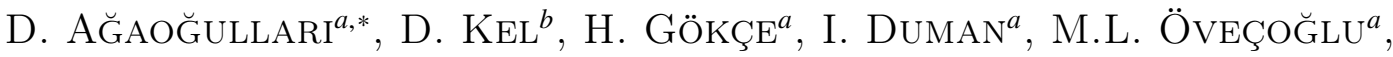 \\ A.T. AkARsubaşi ${ }^{c}$, D. BILGIÇ ${ }^{b}$ AND F.N. OKtaR ${ }^{d, e}$
}

${ }^{a}$ Metallurgical and Materials Engineering Department, Faculty of Chemical and Metallurgical Engineering Istanbul Technical University, Istanbul, Turkey

${ }^{b}$ Analytical Chemistry Department, Faculty of Pharmacy, Marmara University, Istanbul, Turkey

${ }^{c}$ Molecular Biology and Genetics Department, Faculty of Science and Letters

Istanbul Technical University, Istanbul, Turkey

${ }^{d}$ Medical Imaging Technics Department, School of Health Related Professions

Marmara University, Istanbul, Turkey

${ }^{e}$ Nanotechnology Biomaterials Application and Research Center, Marmara University, Istanbul, Turkey

\begin{abstract}
Bioceramic nanopowders, currently one of the most demanding challenges for producing new biomaterials, have been tackled only when starting from chemical reagents. There are few studies aiming at producing hydroxyapatite nanopowders from naturally derived raw materials, such as nacre shells. Natural species of sea origin, such as corals and nacres, always attract special interest in biomaterials science and technology. Nacre shells are made up of pure aragonite crystallized in an organic matrix. The most common way to transform aragonite structures to hydroxyapatite is via hydrothermal transformation under very high pressure. However, such ways can be very dangerous if the equipment is worn. Ultrasonic and hotplate methods are apparently very safe. This work proposes a new approach for developing highly bioactive fine powders of Ca-phosphates (which can be used afterwards to build up hydroxyapatite-based bioceramic bone-scaffolds) from sea urchins via the above mentioned methods. The suspended raw powders were put on a hotplate (i.e. ultrasound). The temperature was set to $80^{\circ} \mathrm{C}$ for 15 min and then, equivalent (to the amount of $\mathrm{CaCO}_{3}$ in the sea urchins) amount of $\mathrm{H}_{3} \mathrm{PO}_{4}$ was added drop by drop into the solution. The reaction continued for $2 \mathrm{~h}$. Then, to evaporate the liquid part, the mixture was put into an incubator at $100^{\circ} \mathrm{C}$ for $24 \mathrm{~h}$ and the resultant dried sediment was collected. X-ray diffraction analysis identified various calcium phosphate phases, predominantly monetite, and tricalcium phosphate as a secondary phase. The worldwide availability and the low cost of all kinds of nacre and sea urchin shells, along with their biological-natural origin are attractive features conferring to them a high potential for preparing calcium phosphate materials for uses in biomedicine. Heart urchin, used in this study, can be an ideal candidate for producing bioceramic particles.
\end{abstract}

PACS: 87.85.jf

\section{Introduction}

Living in the era of life control and prolongation, artificial implants of hydroxyapatite (HA), $\mathrm{Ca}_{10}\left(\mathrm{PO}_{4}\right)_{6}(\mathrm{OH})_{2}$, are very popular for hard tissue (e.g. bone) restorations because they accelerate bone growth around the orthopaedic or dental implant. Biological apatites attract special interest since it is believed that the several substitutions at the $\mathrm{Ca}^{2+}, \mathrm{PO}_{4}^{3}$ and $\mathrm{OH}^{-}$sites of $\mathrm{HA}$ and the presence of several trace elements play an important role in the overall physiological functioning and in the osseointegration process [1]. In the literature there are generally two main types of HA: natural and synthetic HA [2]. Synthetic HA types are produced with classical precipitation method. Natural HA types are produced from various natural sources (i.e. human bone-tooth, bovine bone, sheep bone, chicken bone) with calcination method [3-9]. Besides HA, there are other apatite-like materials which could be easily resorbed at orthopaedic and dental

\footnotetext{
* corresponding author; e-mail: bozkurtdu@itu.edu.tr
}

grafting procedures, like other calcium phosphates with resorable phases ( $\alpha$-tricalcium phosphate, $\beta$-tricalcium phosphate or whitlockite) [10-14]. Tricalcium phosphate (TCP, $\mathrm{Ca}_{3}\left(\mathrm{PO}_{4}\right)_{2}$, also known as tricalcic phosphate) is sometimes referred to simply as calcium phosphate or calcium orthophosphate [15]. Another type of calcium phosphate is monetite, which usually occurs in small quantities in many phosphate deposits, particularly as an incrustation on ancient bones and can transform easily to HA with further chemical reactions or calcination $[16,17]$.

The poor mechanical properties of pure bioceramic materials, such as HA, have directed biomaterials design to tissue-engineering approaches where the mechanical properties of HA can be of relatively minor importance, even in implants with large sizes [1].

Natural species of sea origin, such as corals and nacres, always attract special interest in biomaterials science and technology. In the particular case of oyster shells, the brick-like structure of nacre (also known as "mother of pearl") is made up of pure aragonite (i.e. a polymor- 
phic phase of $\mathrm{CaCO}_{3}$ ) crystallized in an organic matrix. The natural-biological origin of nacres, containing several trace elements that will remain in the crystalline structure of HA and TCP after hydrothermal transformation, making its composition similar to human bone, is expected to benefit the overall physiological functioning after implantation. The production of HA and TCP from natural aragonite via hydrothermal transformation is a known technique since '70s when corals from Pacific Ocean were transformed into Ca-phosphate scaffolds (i.e. TCP) that featured great similarities to the mineralized structure of bones.

There are some reports about the production of HA from nacreous aragonite in the literature [18]. Tuyel et al. had conducted some studies with hotplate and ultrasonic methods using cuttlefish Sepia officinalis, Chinese sweet water pearl powder, the Pacific Kumamoto oyster Crassostrea sikamea, the bivalve mollusk Venus verrucosa and the common European oyster Ostrea edulis. He had prepared nanosized particles of HA and $\beta$-TCP from the materials mentioned above $[19,20]$. There are also few similar studies using urchins. Borzęcka-Prokop et al. had investigated magnesium calcite bio-mineral phases at sea urchin (Paracentrotus lividus from the Adriatic Sea) without applying any hydrothermal conversion and the general formula was magnesium calcium carbonate [21]. Vecchio et al. had conducted classical hydrothermal conversion process converting sea urchin spines using as starting materials diammonium hydrogen phosphate to bioresorbable Mg-substituted tricalcium phosphate $(\beta$ -TCMP). The products showed good bioactivity and osteoconductivity at porous $\beta$-TCMP implants [22]. Vecchio et al. have presented good results on some clams like S. gigas (conch) shell and T. gigas (giant clam) shell [23]. There have been also very successful hydrothermal conversions reported in the study of Rocha et al. using cuttlefish (Sepia officinalis) [1]. Lemos et al. had produced with the same method of Rocha et al. nanoparticles from Mytilus galloprovincialis and Ostrea edulis [18].

The present work aims at broadening the prospects of using urchin shells (specifically, heart urchin - Brissus latecarinatus). This sea urchin was first named by Leske (1778) [24-26]. Heart urchin is widely distributed in Indo-West Pacific, except Arabian Sea [24]. It is also seen in Hawaii area [25, 27]. The hotplate and ultrasonic methods were applied to produce powders of biocompatible and restorable calcium phosphate bioceramics of TCP and monetite which can be used in tissue engineering grafting purposes.

\section{Experimental procedure}

Sea urchin (heart urchin - brissus latecarinatus) samples were obtained from a local shop in Istanbul (Fig. 1, [28]). Urchin shell samples were crushed to produce a powder with particle size $<100 \mu \mathrm{m}$. This powder was analysed with differential thermal and gravimetric analysis (DTA/TG) to determine the exact $\mathrm{CaCO}_{3}$ content of urchin (Fig. 2). According to the results of thermal analysis, the required volume of an aqueous solution of
$\mathrm{H}_{3} \mathrm{PO}_{4}$ was calculated in order to set the stoichiometric molar ratio of $\mathrm{Ca} / \mathrm{P}=3 / 2$ of $\mathrm{TCP}$, as it was shown in a previous study [19].

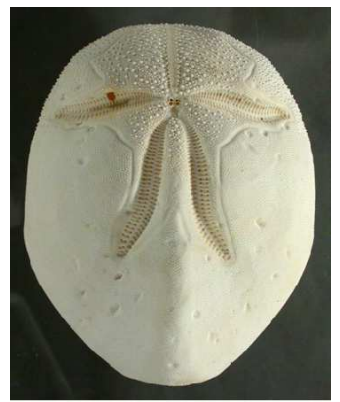

Fig. 1. A skeleton of a heart urchin (there is a visible hole on the upper left-hand side of the urchin which reveals that this urchin was killed by one of the sea snails).

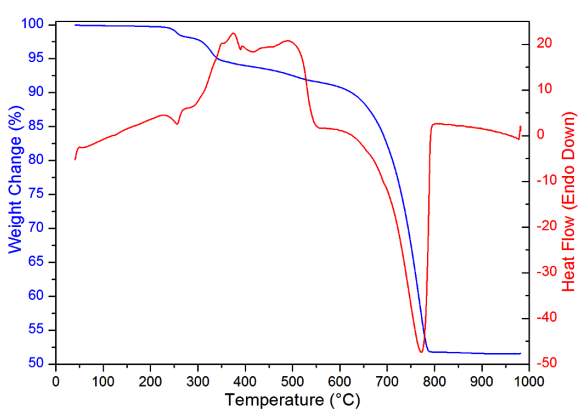

Fig. 2. Differential and gravimetric thermal analysis (DTA/TG) of powders from crushed urchins.

To transform aragonite to Ca-phosphates, two methods were separately applied, which are outlined as follows:

Method 1. The raw powders were suspended in distilled water. The suspension was put in an ultrasonic bath and the temperature was set to $80^{\circ} \mathrm{C}$ for $15 \mathrm{~min}$. Then, equivalent amount (to the $\mathrm{CaCO}_{3}$ content) of $\mathrm{H}_{3} \mathrm{PO}_{4}$ was added drop by drop into the solution. After $2 \mathrm{~h}$ of reaction, the mixture was put into an incubator at $100^{\circ} \mathrm{C}$ for $24 \mathrm{~h}$ to evaporate the liquid part. After complete drying, the resultant sediment was collected.

Method 2. The raw powders were suspended in distilled water. The suspension was put on a hot plate and the temperature was set to $80^{\circ} \mathrm{C}$ for $15 \mathrm{~min}$. Then, equivalent amount (to the $\mathrm{CaCO}_{3}$ content) of $\mathrm{H}_{3} \mathrm{PO}_{4}$ was added drop by drop into the solution. The reaction continued for $2 \mathrm{~h}$. Then, to evaporate the liquid part, the mixture was put into an incubator at $100^{\circ} \mathrm{C}$ for $24 \mathrm{~h}$ and the resultant dried sediment was collected.

In the framework of this study, the processing parameters of the above two synthesis methods were also optimized for each sample. The morphology of the obtained powders was observed in a scanning electron microscope 
(SEM). The crystalline phases of the powders were identified by X-ray diffraction analysis (XRD) and the Fourier transform infrared spectroscopy (FTIR).

\section{Results and discussion}

For the SEM analysis, two types of samples were collected. Before drying the calcium phosphate sediments, liquid samples in the form of droplets were taken from the overlying emulsion zone from each test material. This was done because it was thought that some nanoparticles might be present. Characteristic SEM images from the samples (after drying) obtained from the emulsion zone are presented in Fig. 3. It is clearly seen that this emulsion zone contains only platelets whose thickness is at nanosize, i.e. less than $300 \mathrm{~nm}$.

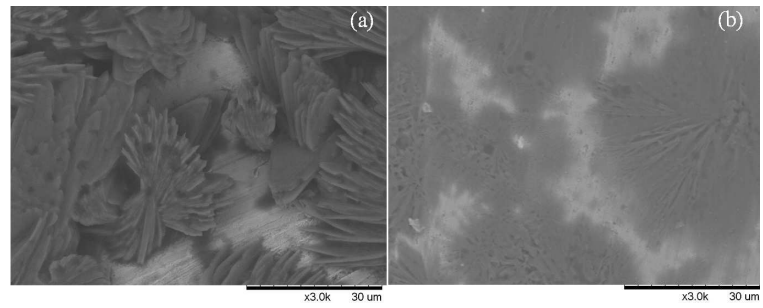

Fig. 3. Particles of monetite and TCP produced in the emulsion zone using (a) the hotplate method and (b) the ultrasonic method.

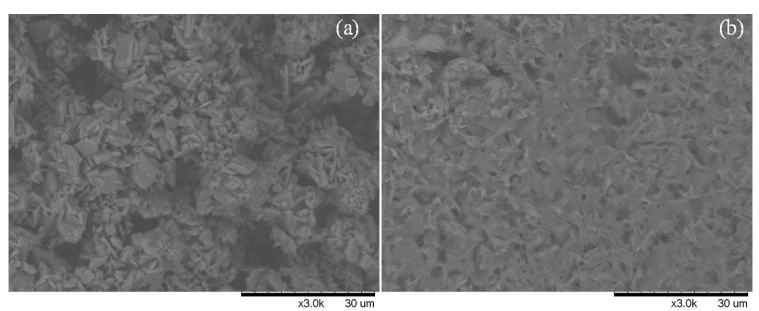

Fig. 4. Particles of monetite and TCP produced from the sediment zone using (a) the hotplate method and (b) the ultrasonic method.

The second type of samples was taken directly from the (still wet) sediment zone. Characteristic SEM images from the samples taken from the sediment zone are presented in Fig. 4. In both cases, the features of the particles approach well submicron characteristics. Moreover, the differences of the morphology of the particles of the powders, likely occurring due to the different methods employed, are apparent. In particular, according to Fig. 4a, the particles formed thin cubicles with a size of ca. $3 \mu \mathrm{m}$. In Fig. 4b, the material surface indicates a wave-like appearance.

The identification of the phases of the particles (at the sediment zone), done with the aid of X-ray diffraction analysis (Fig. 5), indicated that predominantly monetite (ICDD Card No. 70-0359) and TCP (ICDD Card No. $55-0898)$, as a secondary phase, were formed. There is no apparent difference between the diffractograms of the powders produced with the two methods.

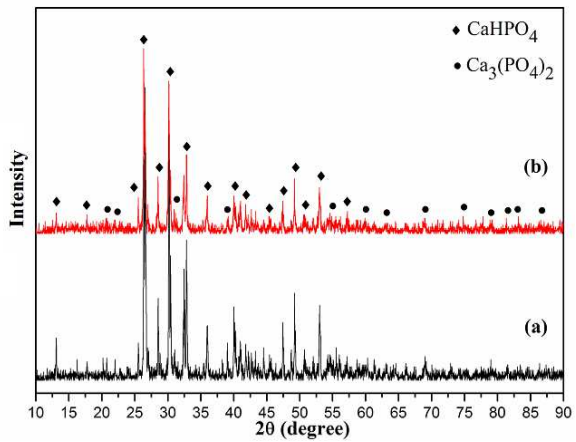

Fig. 5. X-ray diffractograms of the powders produced with (a) the hotplate method and (b) the ultrasonic method. The peaks which correspond to monetite and TCP are also marked.

The FTIR spectra of the powders produced with hotplate method and ultrasonic methods are plotted in Fig. 6. There is also no apparent difference between the spectra of the powders produced with the two methods. The observed bands agree fairly well with the findings of the X-ray analysis, i.e. the presence of monetite and TCP. In particular, the presence of calcium phosphates are concluded because of the characteristic bands of the $\mathrm{PO}_{4}$ tetrahedra which peak at $c a .1398,1341,1127,1060$, $989,881,556,514$, and $396 \mathrm{~cm}^{-1}$.

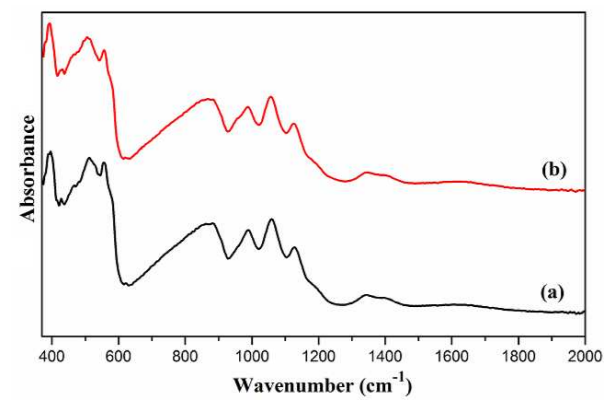

Fig. 6. FTIR spectra of the powders produced with (a) the hotplate method and (b) the ultrasonic method. The bands of the spectra are attributed to monetite and TCP.

The above experimental results show that very delicate monetite and TCP fine particles can be easily produced from sea urchins with hotplate and ultrasonic methods. These particles of monetite and TCP can be used as a very promising source for producing $\mathrm{HA}$, if those particles will be sintered at temperatures above $800^{\circ} \mathrm{C}$.

The sea urchin used in this study is usually found in shallow sandy areas at depths of 0 to $45 \mathrm{~m}$, buried under the sand. It feeds on plants and small invertebrates found between sand particles [24]. With regard to the origin of the raw material, in this study it has been thought that heart urchin could be used as a potential and candidate 
graft material among all other sea creatures, because it is a large sized sea urchin. Some members were found in some other locations of Ujelang Atoll and sand bar east of Moron Island up to length $137 \mathrm{~mm}$, width $105 \mathrm{~mm}$, and height $78 \mathrm{~mm}[29]$.

The introduction also underlined the importance of the biological origin of HA-sources as far as the presence of the trace elements and the ion-substitutions are concerned and their influence on the biological performance of the implant.

With regards to the methods used, it must be underlined that these methods are much safer when compared to the classical hydrothermal conversion methods under high pressures $[1,18]$. They are also much easier and economic since they do not need expensive apparatus but simple, conventional and inexpensive chemical laboratory equipment.

With regards to the produced powders, TCP is a very well known bio-resorbable bioceramic. However, monetite is also an interesting biomaterial precursor. Among several reports on monetite, we can glean from the literature a recent article of Tulyaganov et al. [30]. These authors have reported that when they changed daily stimulated body fluid (SBF) while studying the biomineralization capability of $\mathrm{CaO}-\mathrm{MgO}-\mathrm{SiO}_{2}-\mathrm{Na}_{2} \mathrm{O}-\mathrm{P}_{2} \mathrm{O}_{5}-\mathrm{CaF}_{2}$ bioglass system, monetite $\left(\mathrm{CaHPO}_{4}\right)$ formed, while, the same bioglass favored formation of HA when SBF was not daily changed. This experimental finding shows the close relationship between monetite and $\mathrm{HA}$ and other important Ca-phosphates, like TCP.

Certainly, in vitro osteoblast cell culture tests, which are currently underway, will provide clear evidence about the biocompatibility of the produced powders.

\section{Conclusions}

In this study, the hotplate method and the ultrasonic method were used to successfully transform, under open atmospheric pressure, the aragonite of the heart urchin (brissus latecarinatus), which is a large sized sea urchin in the nature, in Ca-phosphate powders, namely monetite and TCP, whose particles had nanosize features. The used methods are safe and inexpensive. Moreover, the raw materials (sea urchins) feature the advantages of the unlimited source as well as the biological origin. Thus, the produced powders can be qualified for further consideration and experimentation in the light of being used as potential and candidate graft materials.

\section{Acknowledgments}

The authors acknowledge to Asst. Prof. S. Agathopoulos (Materials Science and Engineering Department, Ioannina University, Ioannina, Greece) for helpful discussions.

\section{References}

[1] J.H.G. Rocha, A.F. Lemos, S. Agathopoulos, P. Valério, S. Kannan, F.N. Oktar, J.M.F. Ferreira, Bone 37, 850 (2005).

[2] G. Goller, F.N. Oktar, S. Agathopoulos, D.U. Tulyaganov, J.M.F. Ferreira, E.S. Kayali, I. Peker, J. Sol-Gel Sci. Technol. 37, 111 (2006).
[3] G. Goller, F.N. Oktar, L.S. Ozyegin, E.S. Kayali, E. Demirkesen, Mater. Lett. 58, 2599 (2004).

[4] F.N. Oktar, K. Kesenci, Piskin, Artif. Cell Blood Substit. Immobil. Biotechnol. 27, 367 (1999).

[5] F.N. Oktar, Ceram. Int. 33, 1309 (2007).

[6] G. Goller, F.N. Oktar, Mater. Lett. 56, 142 (2002).

[7] L.S. Ozyegin, F.N. Oktar, G. Goller, E.S. Kayali, T. Yazici, Mater. Lett. 58, 2605 (2004).

[8] U. Karacayli, O. Gunduz, S. Salman, L.S. Ozyegin, S. Agathopoulos, F.N. Oktar, "Effect of sintering temperature on mechanical properties and microstructure of sheep-bone derived hydroxyapatite (SHA)", oral presentation, The 13th Int. Conf. on Biomedical Engineering, Singapore 2008.

[9] N. Demirkol, U. Karacayli, O. Gunduz, S. Agathopoulos, S. Salman, E.S. Kayali, F.N. Oktar, in: Euromat 2009, Glasgow, Glasgow 2009.

[10] S.V. Dorozhkin, Materials 2, 399 (2009).

[11] S.V. Dorozhkin, Materials 2, 221 (2009).

[12] S.V. Dorozhkin, J. Mater. Sci. 42, 1061 (2007).

[13] M. Jarcho, R.L. Salsbury, M.B. Thomas, R.H. Doremus, J. Mater. Sci. 14, 142 (1979).

[14] R.Z. Geros, Advan. Dent. Res. 2, 164 (1988).

[15] http://en.wikipedia.org/wiki/ Calcium_phosphate.

[16] http://www.britannica.com/EBchecked/topic/ 389168/monetite.

[17] M.H. Prado da Silva, J.H.C. Lima, G.A. Soares, C.N. Elias, M.C. de Andrade, S.M. Best, I.R. Gibson, Surf. Coat. Technol. 137, 270 (2001).

[18] A.F. Lemos, J.H.G. Rocha, S.S.F. Quaresma, S. Kannan, F.N. Oktar, S. Agathopoulos, J.M.F. Ferreira, J. Eur. Ceram. Soc. 26, 3639 (2006).

[19] U. Tüyel, M.Sc. Thesis, Marmara University, 2008.

[20] U. Tüyel, E.T. Öner, S. Özyegin, Faik N. Oktar, J. Biotechnol. 131S, S65 (2007).

[21] B. Borzęcka-Prokop, A. Wesełucha-Birczynska, E. Koszowska, J. Mol. Struct. 828, 80 (2007).

[22] K.S. Vecchio, X. Zhang, J.B. Massie, M. Wang, C.W. Kim, Acta Biomater. 3, 785 (2007).

[23] K.S. Vecchio, X. Zhang, J.B. Massie, M. Wang, C. Kim, Acta Biomater. 3, 910 (2007).

[24] http://www.sealifebase.org/summary/ SpeciesSummary $\cdot$ php?id=50027 .

[25] H.L. Clark, A Catalogue of the Recent Sea Urchins (Echinoidea) in the Collection of the British Museum (Natural History), Oxford University, London 1925.

[26] http://www.saltcorner.com/AquariumLibrary/ browsespecies . php?CritterID=3152 .

[27] http://www.marinelifephotography.com/ marine/echinoderms/urchins/brissus latecarinatus.htm .

[28] H. Schultz, Club Conchylia Informationen 37, 41 (2005).

[29] A.H. Clark, Pacific Sci. 8, 243 (1954).

[30] D.U. Tulyaganov, S. Agathopoulos, P. Valerio, A. Balamurugan, A. Saranti, M.A. Karakassides, J.M.F. Ferreira, J. Mater. Sci. Mater. Med. 22, 217 (2011). 